\title{
COMPOSICIÓN NUTRICIONAL DE LAS HOJAS DEL SILBADERO (Geoffroea spinosa Jacq) DEL MUNICIPIO DE TUBARÁ (Atlántico)
}

\section{NUTRITIONAL COMPOSITION OF LEAVES SILBADERO (Geoffroea spinosa Jacq) OF THE MUNICIPALITY OF TUBARÁ}

\author{
*Púa R., Amparo L., Barreto R., Genisberto E., González A., Jessica., Acosta V., César \\ Universidad del Atlántico. Km 7 vía a Puerto Colombia.amparopua@mail.uniatlantico.edu.co, \\ genisbertobarreto@mail.uniatlantico.edu.co, jessicagonzalez1226@hotmail.com, \\ cesar 0724@hotmail.com
}

Recibido 21 de Octubre 2015; aceptado 30 de Marzo de 2016

\section{RESUMEN}

El consumo de frutas y verduras en la alimentación diaria puede prevenir enfermedades crónicas no transmisibles como las cardiovasculares, diabetes mellitus, enfermedades isquémicas del corazón, cerebrovasculares, crónicas de las vías respiratorias y el cáncer, por su elevado contenido de micronutrientes, fibra dietética y compuestos bioactivos; sin embargo el consumo de estos alimentos en Colombia es limitado. El objetivo de esta investigación fue identificar la composición nutricional de las hojas del silbadero (Geoffroea spinosa Jacq) de la finca Los Tres del municipio de Tubará (Atlántico). Para la obtención de la muestras se recolectó la planta, se seleccionaron la hojas, luego se sometieron a lavado, secado y molienda. Se determinaron los parámetros $\mathrm{pH}$, humedad, cenizas, grasas, proteínas, fibra bruta, carbohidratos, zinc, calcio, hierro y magnesio. Los resultados revelaron 6,21 de $\mathrm{pH}, 3,335 \%$ de humedad, 9,531\% de 
*Autor a quien debe dirigirse la correspondencia. Pua R. Amparo .L“ e-mail: amparopua@mail.uniatlantico.edu.co cenizas, 0,639 \% de grasa, 20,535 \% de proteínas, 20,386 \% de fibra bruta, $45,575 \%$ de carbohidratos, $56,53 \mathrm{mg} / 100 \mathrm{~g}$ de zinc, $5793,90 \mathrm{mg} / 100 \mathrm{~g}$ de calcio, 241,27 mg/100 $\mathrm{g}$ de hierro, $3250,64 \mathrm{mg} / 100 \mathrm{~g}$ de magnesio. Las hojas del silbadero son una importante fuente de nutrientes necesarios para la alimentación de los seres humanos, constituyéndose en una alternativa de consumo vegetal por su alto contenido de proteínas, carbohidratos, fibra, calcio y magnesio.

Palabras clave: análisis químico, fibra, micronutrientes, minerales, verduras.

\section{ABSTRACT}

The consumption of fruit and vegetables in the daily diet can prevent chronic noncommunicable diseases such as chronic respiratory and cardiovascular problems, ischaemic of the heart and stroke, diabetes mellitus and cancer, due to its high content of micronutrients, dietary fiber and bioactive compounds; However, the consumption of these foods in Colombia is limited. The objective of this research was to identify the nutritional composition of the leaves of the silbadero (Geoffroea spinosa Jacq) from the farm Los Tres in Tubará municipality (Atlántico). For obtaining of the samples it was collected the plant, the leaves were selected then washed, dried and grinded. Determined parameters $\mathrm{pH}$, moisture, ash, fat, protein, crude fibre, carbohydrates, zinc, calcium, iron and magnesium. Results revealed $6.21 \mathrm{pH}, 3,335 \%$ humidity, 9,531\% ash, 0,639\% fat, 20,535\% protein, $20,386 \%$ crude fibre, 45,575\% carbohydrate, 56,53 mg / $100 \mathrm{~g}$ of zinc, 5793,90 mg / $100 \mathrm{~g}$ calcium, 241,27 mg / $100 \mathrm{~g}$ of iron, 3250,64 mg / $100 \mathrm{~g}$ of magnesium. The silbadero leaves are an important source of nutrients for the feeding of human beings, thus becoming an alternative to vegetable consumption by its high 
content of proteins, carbohydrates, fibre, calcium and magnesium.

Keywords: chemical analysis, fiber, micronutrients, minerals, vegetables.

\section{INTRODUCCIÓN}

Una alimentación adecuada es necesaria para el funcionamiento del cuerpo y la realización de actividades cotidianas; la constituyen una serie de hechos que comienzan desde el cultivo, selección y preparación de alimentos hasta las formas de presentación y el consumo (Hernández, et al. 2004). Desde hace algunos años y debido quizás al reconocimiento a nivel general del papel de la alimentación en la consecución y el mantenimiento de la salud, comenzó una intensa búsqueda, en la mayoría de los casos con gran rigurosidad científica, sobre los alimentos y su efecto sobre la salud. (García, 2007). En los alimentos se pueden encontrar macronutrientes en cantidades relativamente grandes como proteínas, grasas y carbohidratos (OMS, 2015) y minerales importantes como calcio, fósforo, potasio, sodio, cloro, azufre, magnesio, manganeso, hierro, yodo, flúor, zinc, cobalto y selenio (FAO, 2002 ), la importancia de estos elementos radica en que son indispensables para el desarrollo de los procesos químicos y eléctricos del organismo, por lo que es importante que siempre estén en concentraciones equilibradas, pues la carencia o exceso de ellos pueden desencadenar enfermedades. Geoffroea spinosa es un árbol de hoja grande, con tallos y ramas llena de pequeñas espinas; hojas alternas, con flores amarillas, fragantes, en racimos axilares; fruto ovoide, verde amarillento, con mesocarpio carnoso y semillas fusiformes (Oliveira, 2013), la subfamilia Faboideae o Papilionoideae se da en toda América del Sur (Lopes, 2008). En Colombia estos bosques se encuentran representados en su zona norte, en alta Guajira, el alto valle del río Cesar, desde la línea costera del mar Caribe hacia el sur, Barranquilla, Puerto Colombia, Galapa, también en Cúcuta, valle del rio Cauca, Chicamocha (Corporación Autónoma Regional del Atlántico, 2007). La ingesta insuficiente de frutas y verduras es uno de los 10 factores de riesgo principales que contribuyen a la mortalidad atribuible; cada año podrían salvarse hasta 1,7 millones de vidas si hubiera un consumo mundial suficiente de frutas y verduras; el consumo de frutas y verduras variadas garantiza un consumo suficiente de la mayoría de los 
micronutrientes, de fibra dietética y de una serie de sustancias esenciales no nutrientes. Además, el aumento del consumo de frutas y verduras puede ayudar a desplazar los alimentos ricos en grasas saturadas, azúcares o sal (OMS, 2016). Actualmente en Colombia, el consumo de estas fuentes es pobre. El propósito de esta investigación fue identificar la composición nutricional de las hojas del silbadero (Geoffroea spinosa Jacq) de la finca Los Tres del municipio de Tubará (Atlántico).

\section{MATERIALES Y MÉTODOS}

\section{Obtención de la muestra:}

Se seleccionaron las hojas libre de plagas y materiales extraños, se realizó un lavado preliminar, secado bajo la luz solar y finalmente molienda. El material vegetal se almacenó higiénicamente en bolsas de polietileno.

Para la evaluación de la composición nutricional se analizaron por triplicado, tres muestras de $100 \mathrm{~g}$ cada una.

\section{Análisis proximal:}

Para la determinación de proteínas se aplicó el método de Kjeldahl, según la AOAC 2012, con el uso del equipo digestor y de destilación por arrastre de vapor en un equipo Buchi Scrubber B-414 (Estados Unidos); para tal fin se taró aproximadamente $1 \mathrm{~g}$ de la muestra en una balanza analítica y se colocó en los tubos del equipo Kjeldahl, se adicionaron $20 \mathrm{~mL}$ de ácido sulfúrico $\left(\mathrm{H}_{2} \mathrm{SO}_{4}\right)$ al $96 \%$, una mezcla catalizadora, se sometió a digestión la muestra en el equipo hasta que cambio de color entre azul y verde claro, se dejaron enfriar los tubos durante $20 \mathrm{~min}$, se adicionaron lentamente $50 \mathrm{~mL}$ de agua destilada a la muestra digerida, se mezcló y se dejó enfriar, luego se adicionaron $120 \mathrm{~mL}$ de solución de hidróxido de sodio $(\mathrm{NaOH})$ al 20 \%. En un Erlenmeyer se colocaron 100 $\mathrm{mL}$ de ácido bórico al $5 \%$ y 2 gotas de indicador de Tashiro (rojo de metilo $1 \% \mathrm{y}$ azul de metileno $1 \%$ en relación 2:1 en alcohol etílico) bajo la salida de destilación, se recolectó el producto resultante de la destilación, finalmente se tituló con ácido sulfúrico $0.1147 \mathrm{~N}$ y se calculó el porcentaje de proteína, respecto al peso de la muestra seco según la ecuación establecida en el método de referencia.

Para la determinación del contenido de grasa, se empleó el método Soxhlet, descrito en la AOAC 2012; se tararon de 1 a $2 \mathrm{~g}$ de la muestra en una balanza analítica, con el uso de un papel de filtro, luego se colocó en la 
cámara de extracción, se taró el balón vacío que contenía la muestra, se fijó el balón en la parte inferior del equipo Soxhlet en forma segura con la finalidad de evitar evaporación del hexano. En el equipo Soxhlet se colocó el solvente $\mathrm{n}$ - hexano hasta lograr por diferencia de presión el descenso a través del cuello del equipo hasta el balón, luego se añadió $\mathrm{n}$ - hexano hasta cubrir la muestra y se fijó bien el equipo Soxhlet en la parte inferior del refrigerante. La extracción se realizó durante $4 \mathrm{~h}$ controlando el flujo de agua en el refrigerante. Luego de la extracción se recuperó el solvente que se condensó en la cámara de extracción, se dejó enfriar el balón que contenía la grasa y se colocó en la estufa durante una hora con la finalidad de que el $\mathrm{n}$ - hexano se evaporara completamente y se obtuvo solo grasa. Se enfrió a temperatura ambiente, se taró el balón que contenía la grasa. Por último se calculó el porcentaje de grasa según la ecuación establecida en el método de referencia.

Para la determinación de humedad, se empleó el método de desecación, de acuerdo a la AOAC 2012; se tararon de 1 a $2 \mathrm{~g}$ de muestra y la capsula de porcelana vacía previamente lavada y seca. Se colocó la capsula de porcelana con muestra en la estufa de desecación 631 Plus (Comercial Labor S.A., España) y se configuró el equipo a una temperatura de $105{ }^{\circ} \mathrm{C}$ durante $2 \mathrm{~h}$ aproximadamente, se retiró la capsula de la estufa y se dejó enfriar en un desecador, se verificó la pérdida de masa. Nuevamente se colocó la capsula de porcelana en la estufa a $105{ }^{\circ} \mathrm{C}$ durante 15 min para determinar el peso constante, por último dejó enfriar en un desecador y se halló nuevamente el porcentaje de humedad.

Para la determinación de cenizas, se empleó el método incineración a $550{ }^{\circ} \mathrm{C}$, descrito en la AOAC 2012; Luego, se taró el crisol de porcelana, seco y vacío en una balanza analítica Ohaus, se tararon de 1 a $3 \mathrm{~g}$ de muestra aproximadamente, se calcino la muestra durante $2 \mathrm{~h}$ hasta alcanzar $550{ }^{\circ} \mathrm{C}$. Finalmente se dejó enfriar en un desecador y se taró en la balanza analítica. El porcentaje de cenizas se calculó de acuerdo al peso de muestra seca.

La determinación del contenido de carbohidratos se obtuvo por diferencia porcentual de los resultados de proteínas, grasas, fibra, humedad y cenizas.

Para la determinación de fibra, se empleó el método de hidrólisis ácido-básica, con el empleo de un extractor Fiwe 3 Velp Scientifica; las muestras se sometieron a secado en un horno a $105^{\circ} \mathrm{C}$, luego se tararon los crisoles vacíos y $1 \mathrm{~g}$ de la muestra seca y pulverizada. Se reguló el flujo de agua usando $1.5 \mathrm{~L}$ por minuto aproximadamente. 
Se adicionaron $150 \mathrm{~mL}$ de ácido sulfúrico al $1.25 \%$ previamente calentado en la plancha calefactora, se adicionaron de 3 a 6 gotas de alcohol isoamílico y se colocó en el equipo por 30 min aproximadamente; se realizaron tres lavados con agua caliente desionizada, y se adicionó hidróxido de sodio al $25 \%$ en condiciones específicas, luego se realizaron dos lavados con agua desionizada y un tercer lavado con agua fría, finalmente se realizaron tres lavados con $30 \mathrm{~mL}$ de acetona. Los crisoles se secaron a $105^{\circ} \mathrm{C}$ hasta que se obtuvo un peso constante, se determinó primer dato, que representa la fibra cruda más el contenido de ceniza, se llevó el crisol a la mufla a $550{ }^{\circ} \mathrm{C}$ por $2 \mathrm{~h}$, se dejaron enfriar los crisoles en la balanza analítica representando el dato 2 . El porcentaje de fibra se calculó según el método de referencia.

Para la determinación de $\mathrm{pH}$, se empleó un potenciómetro medidor portátil de $\mathrm{pH} / \mathrm{CE} /$ TDS / Temperatura HI 9811-5.

\section{Análisis de minerales:}

Se empleó espectrofotometría de absorción atómica, técnica USP 38. Se realizó curva de calibración con el uso de concentraciones conocidas de los minerales, un estándar de solución a 1000 ppm de magnesio, zinc, hierro y calcio para el posterior análisis de las muestras.
Se tararon aproximadamente $10 \mathrm{~g}$ de muestra seca, la cual se colocó en un crisol de porcelana y se incineró a $600{ }^{\circ} \mathrm{C}$ durante $2 \mathrm{~h}$ aproximadamente. Las cenizas fueron tratadas con $20 \mathrm{~mL}$ de ácido sulfúrico y $4 \mathrm{~mL}$ de ácido nítrico $\left(\mathrm{HNO}_{3}\right)$ concentrado, luego se calentaron hasta disolver el residuo. Una vez la solución se enfrió, se llevó a una volumétrica de $100 \mathrm{~mL}$, se aforo con agua destilada y se obtuvo la primera solución; se tomaron $5 \mathrm{~mL}$ de la solución 1 y se llevaron a una volumétrica de $100 \mathrm{~mL}$, se aforó con agua destilada, luego se tomó de la dilución una alícuota de $10 \mathrm{~mL}$ y se adicionaron 20 $\mathrm{mL}$ de cloruro de lantano $\left(\mathrm{LaCl}_{3}\right)$, se llevaron a una volumétrica de $10 \mathrm{~mL}$ y se aforó con agua destilada.

Para la determinación de magnesio se tomaron $5 \mathrm{~mL}$ de la solución 1, se llevó a una volumétrica de $100 \mathrm{~mL}$ y se aforo con agua destilada, luego se tomó una alícuota de 10 $\mathrm{mL}$ y se adicionaron $20 \mathrm{~mL}$ de cloruro de lactano y se llevó a una volumétrica de 100 $\mathrm{mL}$, nuevamente se aforo con agua destilada. Para el zinc se tomaron $10 \mathrm{~mL}$ de la solución 1 , se llevaron a una volumétrica de $100 \mathrm{~mL}$ y se aforo con agua destilada tipo A. Para el hierro se tomaron $10 \mathrm{~mL}$ de la solución 1, se llevaron a una volumétrica de $100 \mathrm{~mL}$ y se aforo con agua destilada. Para la determinación del calcio, se tomaron $3 \mathrm{~mL}$ de la solución 1 más $20 \mathrm{~mL}$ de cloruro de lantano, se llevaron a una volumétrica de 100 
$\mathrm{mL}$ y se aforo con agua destilada. Se procedió a analizar cada muestra en el espectrofotómetro de absorción atómica, durante 20 a 25 min aproximadamente por cada análisis.

\section{RESULTADOS Y DISCUSIÓN}

Las muestras de las hojas fueron recolectadas en la finca Los Tres del municipio de Tubará (Atlántico), ubicado a $10.8744 \mathrm{~m}$ de latitud, en esta zona se observaron las afectaciones de las plantas a raíz del pastoreo, la tala de los árboles y la elaboración del carbón de leña, lo que probablemente se debe a que esta zona se caracteriza por la presencia de bosques subxerófilo hidrotropofítico caducifolio en donde el silbadero $y$ otras especies espinosas han logrado sobrevivir en condiciones de salinidad (Ministerio de Ambiente, 2016).

La Tabla 1 muestra que los resultados de proteínas, grasa, humedad, fibra, $\mathrm{pH}$ son parecidos y no varían significativamente.

La cantidad de proteínas encontradas en las hojas del silbadero fue significativa en comparación a alimentos existentes en el mercado cotidiano, por ejemplo, huevos $(12,9 \%)$, leche entera $(3,95 \%)$ y carne de res $(21,8 \%)$, y al compararla con el contenido de compuestos nitrogenados en
Análisis estadístico: se estimaron los intervalos de confianza alrededor de la media para cada una de las variables de estudio con un nivel de confianza del $95 \%$. las hortalizas (0.5 a $1.5 \%$ ) (Astiasarán et al, 2002) igualmente se considera elevada.

El contenido de grasas es realmente bajo, lo que difiere con otros estudios que reportan un contenido superior de grasas, como las acelgas $(5,19 \%)$, el bledo $(4,55 \%)$ y la moringa (7.09\%) (Bressani et al, 2014), lo que representa una buena alternativa en la prevención y el control de hiperlipidemias y obesidad, teniendo en cuenta la relación entre la grasa y la secresión de péptidos grastrointestinales conectados con la saciedad y la saciación (Alcalá et al, 2015).

La fibra bruta encontrada representa una cifra alta en comparación con hojas comestibles como la espinaca (2\%), legumbres como la lenteja $(5 \%)$ y frutas como el mango (3\%) (Natursan, 2016).

En los minerales analizados en las hojas del silbadero, el calcio y magnesio se encuentran en mayor cantidad, mientras que el zinc y el hierro se encuentran en menor proporción. Estudios realizados demostraron 
que el nivel suficiente de calcio en las hojas, puede reducir significativamente la actividad de estas enzimas y proteger las células de la planta de invasión de patógenos (Rincón et al, 2015; Navarro, 2013).

La presencia elevada de magnesio enuncia que el silbadero es una planta con un proceso de fotosíntesis adecuado, ayudando a la acumulación de energía y contribuyendo a la adecuada proporción de carbohidratos y proteínas (Guevara et al, 2016).

El zinc y hierro son esenciales en el funcionamiento de muchos sistemas enzimáticos de la planta, el contenido de estos minerales se encuentra en menor cantidad debido normalmente a la aparición de un bloqueo del hierro y zinc en el suelo por pH alto, en los suelos calizos (es decir, que tiene mucha cal y $\mathrm{pH}$ alto) existe la posibilidad de que aparezca este problema en las hojas de la planta llamado clorosis férrica.

Tabla 1. Composición química de las hojas de silbadero.

\begin{tabular}{|l|l|l|l|l|l|}
\hline $\begin{array}{l}\text { Vari } \\
\text { able }\end{array}$ & Media & IC 95 & IC & $\begin{array}{l}\text { Desvi } \\
\text { ación }\end{array}$ & $\begin{array}{l}\text { Varia } \\
\text { nza }\end{array}$ \\
& & & $\begin{array}{l}95 \\
\%\end{array}$ & $\begin{array}{l}\text { están } \\
\text { dar }\end{array}$ & \\
\hline
\end{tabular}

\begin{tabular}{|c|c|c|c|c|c|}
\hline $\begin{array}{l}\text { Prot } \\
\text { eína } \\
\text { s }\end{array}$ & $\begin{array}{l}20,5 \\
2 \%\end{array}$ & $\begin{array}{l}21,3 \\
7\end{array}$ & $\begin{array}{l}16 \\
5\end{array}$ & 0,36 & 0,154 \\
\hline $\begin{array}{l}\text { Gras } \\
\text { as }\end{array}$ & $\begin{array}{l}0,64 \\
\%\end{array}$ & 0,77 & - & 0,06 & 0,003 \\
\hline $\begin{array}{l}\text { Hum } \\
\text { edad }\end{array}$ & $\begin{array}{l}3,33 \\
\%\end{array}$ & 4,04 & $\begin{array}{l}17 \\
66\end{array}$ & 0,31 & 0,125 \\
\hline $\begin{array}{l}\text { Ceni } \\
\text { zas }\end{array}$ & $\begin{array}{l}9,53 \\
\%\end{array}$ & 9,90 & $\begin{array}{l}5,6 \\
0\end{array}$ & 0,16 & - \\
\hline $\begin{array}{l}\text { Carb } \\
\text { ohid } \\
\text { rato } \\
\text { s }\end{array}$ & $\begin{array}{l}45,5 \\
7 \%\end{array}$ & - & - & - & - \\
\hline $\begin{array}{l}\text { Fibr } \\
\text { a }\end{array}$ & $\begin{array}{l}20,3 \\
9 \% \\
\end{array}$ & $\begin{array}{l}15,3 \\
04\end{array}$ & $\begin{array}{l}12 \\
641 \\
\end{array}$ & 0,70 & 0,596 \\
\hline $\mathrm{pH}$ & 6,21 & 6,27 & 5,4 & 0,02 & 0,000 \\
\hline $\begin{array}{l}\text { Mag } \\
\text { nesi } \\
0\end{array}$ & $\begin{array}{l}3249 \\
, 82 \\
\mathrm{mg} / 1 \\
00 \mathrm{~g}\end{array}$ & 3256 & $\begin{array}{l}325 \\
0,5\end{array}$ & 2,37 & 5,593 \\
\hline Zinc & $\begin{array}{l}56,6 \\
7 \\
\mathrm{mg} / 1 \\
00 \mathrm{~g}\end{array}$ & 58,6 & $\begin{array}{l}52 \\
8\end{array}$ & 0,93 & 0,861 \\
\hline $\begin{array}{l}\text { Hierr } \\
0\end{array}$ & $\begin{array}{l}241 \\
31 \\
\mathrm{mg} / 1 \\
00 \mathrm{~g}\end{array}$ & $\begin{array}{l}244, \\
1\end{array}$ & $\begin{array}{l}240 \\
, 1\end{array}$ & 1,28 & 1,627 \\
\hline $\begin{array}{l}\text { Calci } \\
0\end{array}$ & $\begin{array}{l}5793 \\
, 90 \\
\mathrm{mg} / 1 \\
00 \mathrm{~g}\end{array}$ & $\begin{array}{l}5796 \\
, 2\end{array}$ & $\begin{array}{l}579 \\
3,9\end{array}$ & 1,03 & 1,592 \\
\hline
\end{tabular}




\section{CONCLUSIONES}

El silbadero es una planta que crece de manera silvestre en la región Caribe colombiana y su grano es consumido por la población indígena de la misma región. Esta planta no es exigente desde el punto de vista agroclimático.

Las hojas de la planta silbadero son una importante fuente de nutrientes, provechosos para el complemento de la alimentación en los seres humanos.
El contenido de proteínas y fibra convierten las hojas del silbadero en una alternativa de consumo en la alimentación diaria.

No existen estudios que reflejen el uso de las hojas del silbadero en la alimentación humana, pero teniendo en cuenta su composición, puede ser seleccionada para posteriores estudios que potencialicen su consumo.

\section{REFERENTES BIBLIOGRÁFICOS}

Alcalá, Jesús; YAGO, María; MAÑAS, Mariano; LÓPEZ, María; MARTÍNEZ, María; MARTíNEZ, Emilio. Macronutrientes, ingesta de alimentos y peso corporal; papel de la grasa. (2015). Nutrición hospitalaria. 31:46-54.

Astiasarán Iciar, Martínez Alfredo. Alimentos Composición y Propiedades. Segunda edición. Madrid: editorial Mc Graw Hill Interamericana, 2002.

Bressani, Ricardo; Rodas, Brenda; Qudiel, Elsa; Lezema, Claudia. Características químicas y nutricionales de variedades de maicillo: desarrollo de productos alimentarios basados en mezclas de cereales, leguminosas y verduras autóctonas. (2014). Revista de la Universidad del Valle de Guatemala. 27: 49-54.

Corporación Autónoma Regional del Atlántico. Plan de ordenamiento y manejo de la cuencas hidrográficas/2007. http://www.crautonoma.gov.co/index.php/ institucional/plan-de-accion/pomcas.

Consultado: mayo 26 de 2016.

Depósito de documentos de la FAO. Nutrición Humana en el Mundo en Desarrollo, Capítulo 10: Minerales. /2002. Disponible en: [http://www.fao.org/docrep/006/w0073s/w 0073s0e.htm]. Consultado: mayo 8 de 2015. 
García, María. La alimentación del futuro: Nuevas tecnologías y su importancia en la nutrición de la población (2007). An Venez Nutr. 20 (2): 108-114.

Guevara, Luz; Rodríguez, Lizeth; Restrepo, Julio. Evaluación de algunas características físico químicas del suelo y microclima de un bosque secundario para futura adecuación en sistema silvopastoril. 12016). Disponible en: http://repositorio.utp.edu.co/dspace/bitstr eam/11059/6114/1/6360845R696.pdf.

Consultado: junio 62016.

Hernández, Amanda; Armenteros, Mercedes; Lancés, Luisa; Martín, Isabel. Alimentación saludable (2004). Rev Cubana Enfermer. 20 (1): 1-1.

Lopez, Elton, Phytochemical study of Geoffroea spinosa Jacq. (Leguminosae)/ $2008 . \quad$ Disponible en: [http://www.teses.ufc.br/tde_busca/arquiv o.php?codArquivo=2925]. Consultado: mayo 8 de 2015.

Ministerio de Ambiente. Sistema de Gestión Ambiental Municipal, Agenda ambiental Municipio de Tubará./2016). Disponible en:

http://biblovirtual.minambiente.gov.co:300 0/DOCS/MEMORIA/MMA-0412/MMA0412-T5.pdf. Consultado: junio de 2016.
Natursan. Alimentos ricos en fibra./2016). Disponible en: http://www.natursan.net/alimentos-ricosen-fibra-tabla/. Consultado: febrero $13 \mathrm{de}$ 2016.

Navarro, Y. T., Landazabal, L. C., Osorio, L. S. D. Influencia del uso poscosecha de retardante en el color del tomate (Lycopersicum esculentum Mill) variedad Chonto, (2013), @limentech, Ciencia y Tecnología Alimentaria. Vol. 11. № 1. p. 5 $-11$.

Official Methods of Analysis. 19th Ed (2012). Disponible en: http://www.aoac.org/imis15 prod/AOAC Docs/OMA/OMA19Revisions.pdf Consultado: mayo 26 de 2016.

Oliveira Da Silva, Racquel. Polissacarídeos da casca de geoffroea spinosa:caracterização estrutural e atividades anticoagulante e antitrombótica, Universidade Estadual Do Ceará /2013. Disponible en: [http://www.uece.br/cmact/index.php/arqu ivos/doc_download/126-polissacarideosda casca-de-geoffroeaspinosacaracterizacao-estrutural-eatividades-anticoagulante-eantitrombotica]. Consultado: mayo 8 de 2015. 
Organización Mundial de la Salud. Biblioteca electrónica de documentación científica sobre medidas nutricionales (ELENA). /2015. Disponible en línea [http://www.who.int/elena/nutrient/es/]. Consultado: mayo 8 de 2015.

Organización Mundial de la Salud. Programas y proyectos: Estrategia mundial sobre régimen alimentario, actividad física y salud. Fomento del consumo mundial de frutas y verduras. Disponible en: [http://www.who.int/dietphysicalactivity/fru it/es/index1.html] Consultado: junio 6 de 2015.

Rincón, Alfonso, Martínez, Efraín. Funciones del calcio en la calidad poscosecha de frutas y hortalizas: una revisión. (2015). Alimentos hoy. 24 (34): 13-25. 